\title{
Rotavirus infection-associated central nervous system complications: clinicoradiological features and potential mechanisms
}

Kyung Yeon Lee, MD, PhD

Department of Pediatrics, Biomedical Research Center, Ulsan University Hospital, University of Ulsan College of Medicine, Ulsan, Korea

Despite the introduction of vaccines in 2006, rotavirus remains one of the most common causes of pediatric gastroenteritis worldwide. While many studies have conclusively shown that rotavirus infection causes gastroenteritis and is associated with various extraintestinal manifestations including central nervous system (CNS) complications, extraintestinal manifestations due to rotavirus infection have been relatively overlooked. Rotavirus infection-associated CNS complications are common in children and present with diverse clinicoradiological features. Rotavirus infection-associated CNS complications can be classified based on clinical features and brain magnetic resonance imaging findings, particularly lesion location on diffusionweighted imaging. Common clinicoradiological features of rotavirus infection-associated CNS complications include: (1) benign convulsions with mild gastroenteritis; (2) acute encephalopathies/encephalitis, such as mild encephalopathy with a reversible splenial lesion, acute encephalopathy with biphasic seizures and late reduced diffusion, and acute necrotizing encephalopathy; (3) acute cerebellitis; and (4) neonatal rotavirus-associated leukoencephalopathy. The precise mechanism underlying the development of these complications remains unknown despite a number of clinical and laboratory studies. Here we review the diverse clinicoradiological features of rotavirus infection-associated CNS complications and propose a hypothesis of their pathophysiology.

Key words: Rotavirus, Central nervous system, Complications, Neurologic manifestations, Pathophysiology

\section{Key message}

- Rotavirus infection-associated central nervous system (CNS) complications are fairly common in children.

- Common clinicoradiological features include benign convulsions with mild gastroenteritis, acute encephalopathies/encephalitis, cerebellitis, and neonatal rotavirus-associated leukoencephalopathy.

- Possible mechanisms for CNS complications include direct viral invasion into the brain via several potential routes such as the blood-brain barrier and vagus nerve, and entry of various brain-damaging mediators and activated immune cells into the brain.

\section{Introduction}

Rotavirus, one of the most common pathogens causing gastroenteritis among children under 5 years of age, is the leading cause of pediatric diarrhea-related deaths worldwide. ${ }^{1)}$ Before the introduction of vaccines, rotavirus gastroenteritis was responsible for the deaths of more than 500,000 children annually. ${ }^{2)}$ Since 2006, rotavirus vaccines have been introduced in more than 100 countries and significantly reduced the global burden of rotavirus disease. ${ }^{3)}$ During the first 10 years after vaccine introduction into the national immunization schedule for children, rotavirus disease-associated hospitalizations decreased by $67 \%$ (range, $18 \%-84 \%$ ) and all-cause diarrhea-related deaths decreased by $42 \%$ (range, 3\%-64\%). ${ }^{4,5)}$ In addition, rotavirus vaccination has reportedly decreased the hospitalizations for acute gastroenteritis-associated seizures in children $<5$ years old in several countries, including the US, Japan, the UK, Spain, and Korea. ${ }^{6-11)}$ Nevertheless, rotavirus gastroenteritis still causes more than 200,000 deaths annually. ${ }^{12)}$ Rotavirus was first reported in 1973 after the visualization of viral particles under an electron microscope in the duodenal mucosa of 9 children with acute nonbacterial gastroenteritis. ${ }^{13)}$ Rotavirus infection was initially considered confined to the gastrointestinal tract; however, many reports have shown that it may cause extraintestinal manifestations including various neurological disorders, hepatitis, cholestasis, pancreatitis, type 1 diabetes, respiratory illness, myocarditis, renal failure, and thrombocytopenia. ${ }^{14,15)}$ Rotavirus is a common cause of acute encephalopathy and encephalitis in children. ${ }^{16-19)}$ Since the first report of central nervous system (CNS) involvement with rotavirus in 1978 (one fatal Reye's syndrome case, one encephalitis case), ${ }^{20)}$ a variety of rotavirus infection-associated CNS complications, such as convulsions

Corresponding author: Kyung Yeon Lee, MD, PhD. Department of Pediatrics, Ulsan University Hospital, 25, Daehakbyeongwon-ro, Dong-gu, Ulsan 44033, Korea 凶Email: pdsnoopy@naver.com, https://orcid.org/0000-0001-6821-1056

Received: 29 August 2021, Revised: 6 December 2021, Accepted: 22 January 2022

This is an open-access article distributed under the terms of the Creative Commons Attribution Non-Commercial License (http://creativecommons.org/licenses/bync/4.0/) which permits unrestricted non-commercial use, distribution, and reproduction in any medium, provided the original work is properly cited.

Copyright (c) 2022 by The Korean Pediatric Society 
with mild gastroenteritis, ${ }^{21-23)}$ aseptic meningitis, ${ }^{24)}$ mild encephalopathy with reversible splenial lesions, ${ }^{25-27)}$ encephalitis, ${ }^{28,29)}$ and cerebellitis, ${ }^{30)}$ have been documented. Although rotavirus infection can involve CNS complications with various manifestations, such as impaired consciousness, seizures, and mutism, the underlying mechanisms by which rotavirus infection causes these complications are largely unknown.

This study aimed to examine the diverse clinicoradiological features and propose mechanisms of rotavirus infection-associated CNS complications based on previously published studies.

\section{Clinicoradiological features of rotavirus infection-associated CNS complications}

\section{Benign convulsions with mild gastroenteritis}

Benign convulsions with mild gastroenteritis are among the most common neurological manifestations related to rotavirus infection in children, occurring in approximately 1\%-8\% of patients with rotavirus gastroenteritis. ${ }^{14,31-34)}$ Although it has been documented worldwide, the number of reported cases is considerably higher in East Asian countries, particularly Japan, Korea, Taiwan, and China. ${ }^{21-23,35-37)}$ This clinical condition is seen in previously healthy children aged 1 month to 6 years (peaking in 1-2-year-olds) and present with afebrile (or febrile) seizures that develop 1-6 days after gastroenteritis onset. ${ }^{34,35)}$ Some children experience seizures 12-24 hours before or even on the same day as the onset of diarrhea. Patients show neither electrolyte imbalance nor severe dehydration. Although seizures are usually the generalized tonic-clonic type, ictal electroencephalography has almost always demonstrated focal onset followed by secondary generalization. ${ }^{34,38)}$ Findings on interictal electroen- cephalography, cerebrospinal fluid (CSF) analysis, and magnetic resonance imaging (MRI) are almost always normal (Table 1). Some patients show lesions in the splenium of the corpus callosum on diffusion-weighted imaging (DWI). ${ }^{39)}$ Rotavirus and norovirus antigens are frequently identified in stool samples from these patients, and rotavirus ribonucleic acid (RNA) or antigens have also been detected in CSF samples in some cases. ${ }^{40-42)} \mathrm{Al}$ though patients commonly have multiple seizures, the outcome is favorable, with rare relapse, unimpeded development, and no epilepsy. ${ }^{34)}$

\section{Acute encephalopathies and encephalitis}

As mentioned above, rotavirus commonly causes acute encephalopathy and encephalitis in children. In Japan, 2 national surveys were conducted of the epidemiology of pediatric acute encephalopathy during 2007-2010 and 2014-2017. ${ }^{17,18)}$ Interestingly, rotavirus was ranked third among the identified pathogens of antecedent infection in acute encephalopathy in both surveys. Influenza virus and human herpes virus 6/7 placed first and second, respectively. In rotavirus-associated encephalopathy, the median age at onset was 2 years in both studies. A recent Swedish prospective cohort study also showed that rotavirus was the third most common pathogen implicated in childhood encephalitis. ${ }^{19)}$ In 61 of 89 cases (68.5\%), the etiologies of encephalitis were established. The common viral etiologies included tick-borne encephalitis virus $(n=13)$, enterovirus $(n=$ $10)$, and rotavirus $(\mathrm{n}=9)$.

In general, since viral infection-associated acute encephalopathy and viral encephalitis present with similar brain dysfunc. tion such as acute onset altered consciousness and seizures, it is often difficult to distinguish them from each other; thus, the terms are sometimes used interchangeably in the clinical

Table 1. Diverse clinicoradiological spectrum of rotavirus infection-associated central nervous system (CNS) complications

\begin{tabular}{|c|c|c|c|}
\hline Types of CNS complications & Typical clinical features & Characteristic MRI findings & Prognosis \\
\hline $\begin{array}{l}\text { Benign convulsions with mild gastro- } \\
\text { enteritis }\end{array}$ & $\begin{array}{l}\text { Usually, afebrile generalized seizures after diarrhea and/or } \\
\text { vomiting; neither electrolyte imbalance nor severe } \\
\text { dehydration; normal in CSF analysis and interictal EEG }\end{array}$ & Normal & Favorable \\
\hline \multicolumn{4}{|l|}{ Acute encephalopathies/encephalitis } \\
\hline MERS & $\begin{array}{l}\text { Delirious behavior, decreased consciousness, and seizures; } \\
\text { normal in CSF analysis }\end{array}$ & $\begin{array}{l}\text { Homogenous high signal in the sple- } \\
\text { nium of corpus callosum on DWI }\end{array}$ & Favorable \\
\hline AESD & $\begin{array}{l}\text { Biphasic seizures (an initial prolonged febrile seizure on } \\
\text { days 1-2, followed by a cluster of complex partial seizures } \\
\text { on days 3-7) together with impaired consciousness }\end{array}$ & $\begin{array}{l}\text { High signal in subcortical white matter } \\
\text { (bright tree appearance) on DWI } \\
\text { performed between days } 3 \text { and days } 9\end{array}$ & Various \\
\hline ANE & $\begin{array}{l}\text { Fulminant progression of impaired consciousness and } \\
\text { seizures; Normal cell counts and increased protein level } \\
\text { in CSF analysis }\end{array}$ & $\begin{array}{l}\text { Bilateral thalamic lesions in an oval } \\
\text { shape with low } \mathrm{T} 1 \text { and high } \mathrm{T} 2 \text { signal } \\
\text { and restricted diffusion on days } 1-2\end{array}$ & Fatal \\
\hline Acute cerebellitis & $\begin{array}{l}\text { Impaired consciousness after the onset of symptoms of } \\
\text { gastroenteritis followed by mutism with other cerebellar } \\
\text { symptoms; Presence of CSF pleocytosis }\end{array}$ & High signal in cerebellum on DWI & Various \\
\hline $\begin{array}{l}\text { Neonatal rotavirus-associated leuko- } \\
\text { encephalopathy }\end{array}$ & $\begin{array}{l}\text { Repetitive focal or multifocal clonic seizures at around } 5 \text { days } \\
\text { of age in healthy full-term newborns without perinatal } \\
\text { problems; uncommon gastrointestinal symptoms and no } \\
\text { fever; main cause of fifth day seizures; normal in CSF } \\
\text { analysis }\end{array}$ & $\begin{array}{l}\text { High signal in bilaterally symmetric } \\
\text { diffuse white matter including corpus } \\
\text { callosum on DWI }\end{array}$ & Various \\
\hline
\end{tabular}

MRI, magnetic resonance imaging; CSF, cerebrospinal fluid; EEG, electroencephalography; MERS, mild encephalopathy with a reversible splenial lesion; DWI, diffusion-weighted imaging; AESD, acute encephalopathy with biphasic seizures and late reduced diffusion; ANE, acute necrotizing encephalopathy. 
setting. Encephalitis typically shows inflammation of the brain parenchyma, while acute encephalopathy shows pathologically widespread noninflammatory brain edema that is either cytotoxic (cellular) or vasogenic (vascular). ${ }^{43)}$ In principle, although the presence of CSF pleocytosis favors a diagnosis of encephalitis, an absence of CSF pleocytosis in patients with viral encephalitis is not uncommon. ${ }^{44)}$ On brain MRI, viral encephalitis tends to demonstrate asymmetrical focal or multifocal lesions as seen in herpes simplex virus encephalitis, ${ }^{45)}$ while acute encephalopathy is disposed to show bilaterally symmetrical lesions. ${ }^{16)}$ Both conditions may reveal normal MRI findings.

Another nationwide survey of rotavirus-associated encephalitis/encephalopathy and sudden unexpected death conducted in Japan between 2009 and 2011 showed that, among a total of 58 cases of rotavirus-associated encephalitis/encephalopathy and 7 cases of sudden unexpected death, 36 patients (62.1\%) with encephalitis/encephalopathy had no sequelae, while 15 (25.9\%) had neurological sequelae and 7 (12.1\%) had fatal outcomes. ${ }^{46)}$ Pleocytosis was observed in 9 of 40 patients $(22.5 \%)$. Elevated lactate dehydrogenase levels (>500 IU/L) or acidemia ( $\mathrm{pH}<7.15$ ) were associated with poor prognosis.

Viral infection-associated acute encephalopathy is classified according to the pathogenic virus of antecedent infection, such as rotavirus-associated encephalopathy or influenza-associated encephalopathy. Alternatively, based on clinical manifestations and brain MRI findings, it can be classified as various syndromes, such as acute necrotizing encephalopathy (ANE), acute encephalopathy with biphasic seizures and late reduced diffusion (AESD), mild encephalopathy with a reversible splenial lesion (MERS), hemiconvulsion-hemiplegia-epilepsy syndrome, hemorrhagic shock and encephalopathy syndrome, Reye's syndrome, and so forth, although unclassified acute encephalopathy is the most common. ${ }^{16}$ ) According to the Japanese national surveys of 2007-2010 and 2014-2017, MERS was the most common syndromic diagnosis of rotavirus-associated encephalopathy (18 cases [45.0\%]), followed by AESD (4 cases [10\%]) and ANE (1 case [2.5\%]) in the first study. The order was the same in the second survey as well: MERS (21 cases [46.7\%]), AESD (5 cases [11\%]), and ANE (2 cases [4.4\%]). ${ }^{17,18)} \mathrm{A}$ full recovery was observed in 28 (70.0\%) and 31 cases (68.9\%), while neurologic sequelae were seen in 8 (20.0\%) and 13 cases (28.9\%) in the first and second survey, respectively. Three (7.5\%) and 0 deaths $(0 \%)$ were reported in the respective surveys. Here we describe the typical findings of MERS, AESD, and ANE.

\section{1) Mild encephalopathy with a reversible splenial lesion}

MERS typically presents with mild encephalopathy following prodromal symptoms such as fever, cough, vomiting, and diarrhea. Delirium (54\%), decreased consciousness (35\%), and seizures (33\%) were the most common neurological symptoms. ${ }^{16,47,48)}$ On MRI, the splenium of the corpus callosum shows a homogenous high signal on DWI (Fig. 1A). ${ }^{49)} \mathrm{T} 1$ and T2 signal changes are mild without enhancement during the acute period. Reversible diffusion restriction in the splenium of the corpus callosum has been reported in various conditions, such as diverse infections, withdrawal of antiepileptic drugs, altitude sickness, Kawasaki disease, and hyponatremia. ${ }^{16}$ A Japanese national survey showed that MERS was the second most common pediatric acute encephalopathy, accounting for 16\% of cases. ${ }^{16)}$ Among MERS-related pathogens, rotavirus was ranked second (12\%), following influenza virus (34\%). ${ }^{18)}$ The prognosis of MERS is generally favorable, with complete resolution regardless of treatment. ${ }^{17,47,48)}$ The high signal on DWI disappears within 2 months, leaving no atrophy. ${ }^{17)}$

2) Acute encephalopathy with biphasic seizures and late reduced diffusion

AESD is clinically characterized by biphasic seizures, that is, an initially prolonged febrile seizure on days $1-2$, followed by a cluster of complex partial seizures on days 3-7 in conjunction with impaired consciousness. ${ }^{16}$ Between the early and late seizures, some patients (20\%-30\%) have normal consciousness with no neurological symptoms. MRI shows distinctive diffusion restriction in the subcortical white matter (bright tree appearance) on days 3-9.48,50,51) AESD has been predominantly reported in Japan, with an annual incidence of 100-200 cases. ${ }^{17,18)}$ The most common associated pathogens are human herpesvirus 6 (38\%), followed by influenza virus (10\%) and rotavirus (2\%). ${ }^{16}$ DWI of MRI performed on days 1 and 2 usually shows no abnormalities, which may lead to an initial misdiagnosis of febrile status epilepticus. Clinical outcomes vary from normal to severe intellectual disability, paralysis, and epilepsy. ${ }^{52)}$ The mortality rate is relatively low $(<5 \%)$. A recent study showed that a better prognosis was associated with a first seizure duration of less than 30 minutes and smaller MRI lesions (mainly in frontal areas). ${ }^{52}$ )

\section{3) Acute necrotizing encephalopathy}

ANE is characterized by the fulminant progression of impaired consciousness, seizures, bilateral thalamic lesions on MRI, and catastrophic outcomes. ${ }^{16)}$ ANE has been reported worldwide, but it appears to be more prevalent in East Asian countries such as Japan, Taiwan, and Korea. ${ }^{53-56)}$ Coma and seizures are very frequent, while vomiting and diarrhea are also common. ${ }^{16)}$ Shock may occur early after onset in severe cases. Bilateral symmetric thalamic lesions are a key feature of ANE. Thalamic lesions are oval-shaped (Fig. 1B). ${ }^{16,55)}$ On days $1-2$, the lesions showed low T1 and high T2 signal intensity accompanied by restricted diffusion. On day 3 and beyond, the thalamic lesions showed a concentric appearance due to T1 high-signal lesions in the central areas, indicating hemorrhagic changes. Apart from the thalamus, lesions are often observed in the periventricular white matter, internal capsule, putamen, upper brainstem tegmentum, and cerebellum. A CSF analysis shows normal cell counts and an increase in protein levels in twothirds of patients. ${ }^{16)}$ Although an effective treatment for ANE is lacking, a retrospective study showed that steroid pulse therapy or intravenous dexamethasone within 24 hours after disease 

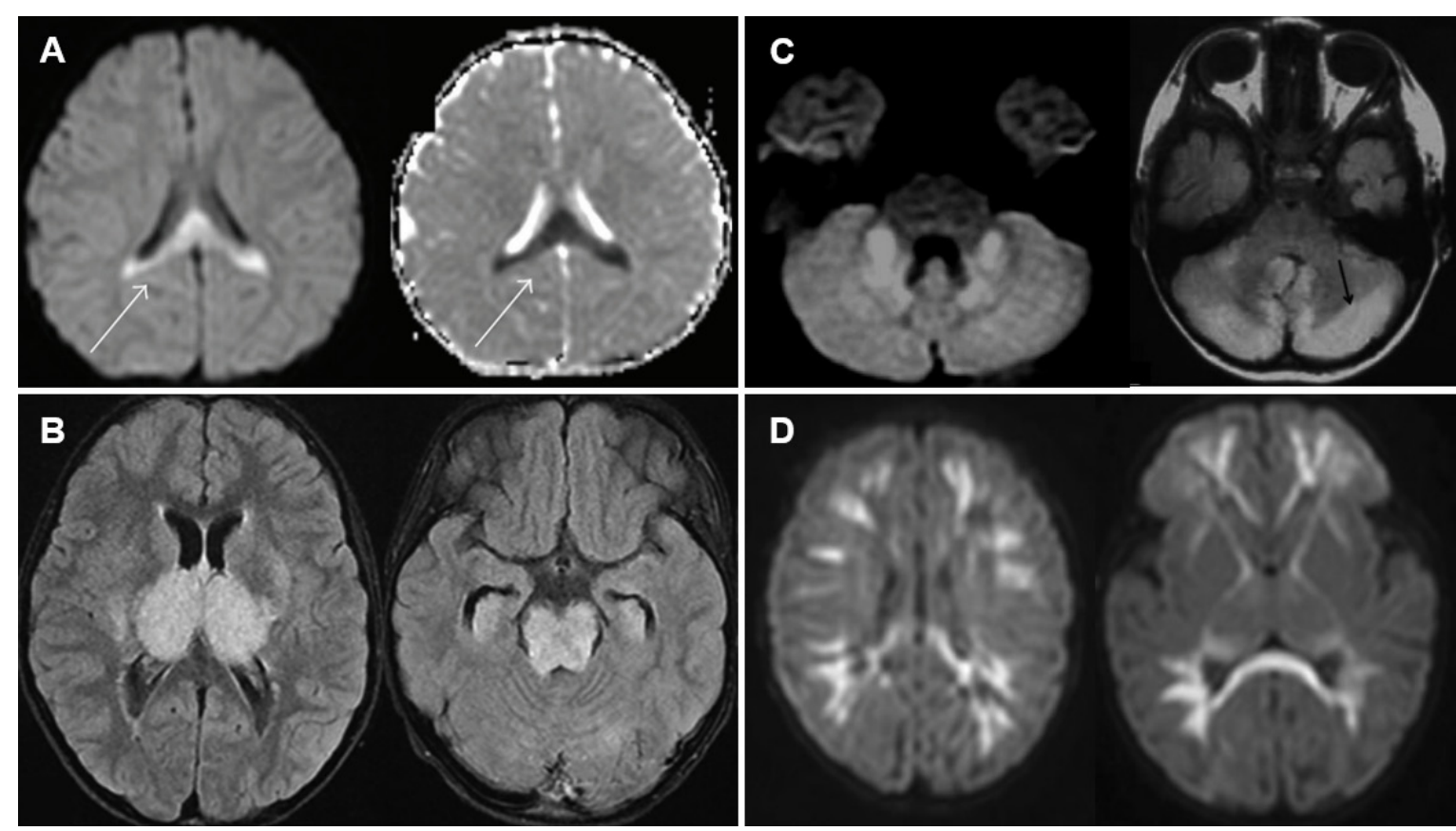

Fig. 1. Characteristic magnetic resonance imaging findings of rotavirus infection-associated central nervous system complications. (A) Mild encephalopathy with a reversible splenial lesion. Note the diffusion restriction of the splenium in the corpus callosum (arrow). Reproduced from reference 49 (Copyright 2013, Hindawi Publishing Corp.). (B) Acute necrotizing encephalopathy. Note the hyperintensity of the thalamus in the oval shape, the basal ganglia, and the midbrain. Reproduced from reference 55 (Copyright 2020, Formosan Medical Association). (C) Acute cerebellitis. Note the diffusion restriction of the cerebellar peduncle and nuclei, and the high-signal intensity in the cerebellar cortex (arrow). Reproduced from reference 30 (with permission from American Society of Neuroradiology). (D) Neonatal rotavirus-associated leukoencephalopathy. Note the diffusion restriction of the bilateral diffuse cerebral white matter extending to the subcortical regions, corpus callosum, internal capsule, and posterior portion of the thalamus. Reproduced from reference 64 (with permission from Elsevier).

onset was associated with better prognosis in patients without brainstem lesions. ${ }^{57)}$ The reported mortality rate of ANE is approximately 30\%, and most affected children die in the first week. ${ }^{58-61)}$ Survivors of ANE suffer from mild to moderate neurologic sequelae, and approximately $10 \%$ of patients recover completely. ${ }^{55,59)}$

\section{Acute cerebellitis}

Rotavirus cerebellitis is characterized by decreased consciousness 1-3 days after the onset of symptoms of gastroenteritis and subsequent mutism. ${ }^{30)}$ Consciousness clears between days 4 and 12, but mutism is observed after the recovery of consciousness. Mutism may last for up to 20 days. Other possible cerebellar symptoms include slow speech or dysarthria, hypotonia, ataxia, tremors, nystagmus, and dysmetria. MRI, particularly DWI, shows high-signal intensity in the bilateral dentate nuclei/cerebellar white matter in the acute and subacute phases, followed by increased signal intensity in the vermis and cerebellar cortex, and finally cerebellar atrophy 1-2 months after onset (Fig. 1C). ${ }^{30,62)}$ Concomitant reversible splenial lesions are often observed during the acute phase. ${ }^{63)}$ CSF pleocytosis is frequently observed along with normal glucose and protein levels. Despite treatment with corticosteroids and intravenous immunoglobulins, many patients show mild to moderate cerebellar symptoms such as ataxia, dysarthria, tremors, and mental retardation. ${ }^{30)}$

\section{Neonatal rotavirus-associated leukoencephalopathy}

Neonatal rotavirus-associated leukoencephalopathy typically presents with repetitive or clustered focal or multifocal clonic seizures at around the 5th day after birth accompanied by bilaterally symmetric diffuse white matter and corpus callosum lesions on DWI. ${ }^{64)}$ We recently demonstrated that neonatal rotavirus-associated leukoencephalopathy was a main cause of fifth-day seizures, which prevailed in European countries and Australia between the 1970s and mid-1980s based on the similarity of clinical features and the annual incidence of an epidemic-like outbreak with abrupt disappearance. ${ }^{65)}$ Since the first report by our institute in $2014,{ }^{64)}$ most cases of neonatal rotavirus-associated leukoencephalopathy have been documented in Korea, particularly in the confined southeast province of Korea, including Ulsan, Busan, and Jinju. ${ }^{66-68)}$ Between 2008 and 2016, in our institute, rotavirus-associated leukoencephalopathy accounted for $37.2 \%$ of neonatal seizures in full-term newborns, which peaked at $70.6 \%$ in 2012, gradually decreased, and finally disappeared in 2017. Seizures usually occur in healthy full-term newborns without a history of perinatal asphyxia. There is no known cause of neonatal seizures, such as hypoxic-ischemic encephalopathy or intracranial hemorrhage. Lesions on DWI are observed in symmetric diffuse patterns involving the cerebral white matter and corpus callosum. Lesions on DWI often extend to the internal capsule, external capsule, thalamus, basal ganglia, and brain stem following the white matter tracts (Fig. 1D). ${ }^{64)}$ Only a small number of patients have gastrointestinal 
symptoms, such as diarrhea and vomiting, despite rotavirus infection. Almost all patients had no fever or rashes. Neither rotaviral RNA nor antigen was detected in CSF samples. ${ }^{66,68)}$ CSF pleocytosis was also not observed. Some patients showed a decrease in cerebral white matter volume and cerebromalacia in the white matter on follow-up MRI taken after 1-3 months. ${ }^{67)}$ Our previous study demonstrated that 18 of 32 patients (56\%) with neonatal rotavirus-associated leukoencephalopathy had delayed performance on the mental and/or motor scales of the Korean Bayley Scales of Infant Development II assessment at a median age of 22 months. ${ }^{69)}$ The lesion extent on initial DWI was negatively correlated with the mental developmental scale.

\section{Other rare CNS complications}

Posterior reversible encephalopathy syndrome, ${ }^{70)}$ opsoclonusmyoclonus syndrome, ${ }^{71)}$ and hemiconvulsion-hemiplegia-epilepsy syndrome ${ }^{72)}$ are reportedly related to rotavirus infection as described in previous case reports.

\section{Proposed potential mechanisms of rotavirus infection-associated CNS complications}

The detection of rotavirus antigens and RNA in the CSF of patients with CNS complications supports the theory of direct viral invasion of the CNS. ${ }^{27,73-75)}$ However, CSF samples are not always positive for rotavirus antigen and/or RNA in cases of CNS complications. ${ }^{66,68)}$ Considering these observations, it is presumed that CNS complications may be caused by direct viral invasion of the CNS and/or circulating mediators with deleterious effects on the CNS. Here we review the structure of rotavirus, the histologic findings of rotavirus infection in enterocytes, and the role of rotavirus nonstructural protein 4 (NSP4), the most investigated protein in rotavirus infection at the molecular level. We subsequently propose the possible mechanisms of rotavirus infection-associated CNS complications as an overall entity rather than by each clinicoradiological type.

\section{Rotavirus structure and classification}

Rotavirus is a nonenveloped double-stranded RNA virus with a wheel-like icosahedral structure composed of 3 concentric capsids that surround a genome of 11 segments of RNA. ${ }^{1,76}$ ) These RNA segments encode 6 structural viral proteins (VP1-4, VP6, and VP7) and 6 nonstructural proteins (NSP1-NSP6). Among the 6 structural proteins, surface glycoprotein VP7 and spike protein VP4 constitute the outermost layer and are responsible for eliciting an immune response. VP6 constitutes the middle capsid layer; based on the sequence and antigenic differences of VP6, rotavirus is classified into 10 different species (A-J). ${ }^{77)}$ Species A rotavirus is the most common cause of infection in children. ${ }^{1)}$ Rotavirus is further classified into diverse genotypes based on sequence differences in RNA segments 7 and 4, which encode VP7 and VP4, respectively. VP7 and VP4 subtypes determine the $\mathrm{G}$ and $\mathrm{P}$ genotypes, respectively, in a dual classification system. $^{76}$

\section{Histologic findings in rotavirus gastroenteritis}

Rotavirus predominantly infects mature enterocytes at the top and middle of the intestinal villi, leading to the vacuolization of enterocytes. ${ }^{1)}$ Rotavirus infection and replication in the duodenal mucosa of infants cause shortening and atrophy of the villi, loss of microvilli, mononuclear cell infiltration, distended endoplasmic reticulum, and mitochondrial swelling in enterocytes. ${ }^{78,79)}$ The suggested mechanisms underlying these findings include virus-mediated apoptosis, ${ }^{80)}$ NSP4-mediated mislocalization of the ZO-1 tight junction protein, ${ }^{81)}$ binding to the basement membrane extracellular matrix proteins laminin subunit- $\beta 3$ and fibronectin ${ }^{82)}$ and disruption of normal cellular homeostasis. ${ }^{83)}$ Previous in vitro studies demonstrated that rotavirus is able to infect neuronal cells, where NSP4 was detected. ${ }^{84,85)}$ Thus, rotavirus infection may cause a change in cellular structure and function, leading to cell death of neurons as well as enterocytes.

\section{Rotavirus NSP4}

Rotavirus NSP4 is a well-known viral enterotoxin that functions as a viroporin for the disruption of intracellular $\mathrm{Ca}^{2+}$ homeostasis through phospholipase C. ${ }^{1)}$ Viroporins are small virus-encoded ion channel proteins. ${ }^{86}$ Rotavirus infection and NSP4 expression alone can increase cytoplasmic $\mathrm{Ca}^{2+}$ levels resulting from increased $\mathrm{Ca}^{2+}$ leakage from the endoplasmic reticulum via NSP4 viroporin. ${ }^{86,87)}$ The elevation of cytoplasmic $\mathrm{Ca}^{2+}$ levels is critical to the rotavirus replication process, including activation of autophagy, nucleation of rotavirus replication complexes called viroplasms, and assembly of the outer capsid protein VP7. ${ }^{86,87)} \mathrm{NSP} 4$ can also induce the production of nitric oxide and its metabolites. The overproduction of reactive nitrogen species is known to alter protein structure, thereby inhibiting their normal function, leading to DNA fragmentation and lipid oxidation. ${ }^{88)}$ One study showed that the treatment of intestinal cells with NSP4 increased inducible nitric oxide synthase mRNA expression. ${ }^{89)}$ Another study showed that the incubation of human intestinal epithelial cells with purified NSP4 caused $\mathrm{NO} 2 / \mathrm{NO} 3$ accumulation in the incubation media. ${ }^{87}$ In this study, 46 children with rotavirus infection showed higher urinary $\mathrm{NO} 2 / \mathrm{NO} 3$ concentrations compared to their agematched peers. Previous studies showed that inducible nitric oxide synthase activity depends on intracellular calcium levels and that NSP4 increases intracellular calcium levels. Thus, the authors interpreted that NSP4 increases NO production by elevating intracellular calcium levels. Rotavirus NSP4 can also elicit the production of proinflammatory cytokines, and a recent report demonstrated that NSP4 induces the secretion of proinflammatory cytokines such as interleukin (IL)- 6 and tumor necrosis factor (TNF)- $\alpha$ together with nitrite from human and murine macrophage-like cell lines via Toll-like receptor $2 .{ }^{90)}$ Another study showed that NSP4 induced the time-dependent generation of reactive oxygen species (ROS) in human intestinal epithelial cells. ${ }^{91)}$ Given that ROS can induce intestinal epithelial 


\begin{abstract}
1. Direct viral invasion into the CNS
Means of entry

(A) Hematogenous spread via the blood-brain barrier, the blood-CSF barrier, or capillaries of circumventricular organs

(B) Access via peripheral nerves such as vagus nerve

2. CNS entry of brain-damaging mediators ${ }^{\text {a) }}$ produced by rotavirus infection through breach of the blood-brain barrier and the blood-CSF barrier

3. CNS entry of activated circulating leukocytes

CNS, central nervous system; CSF, cerebrospinal fluid.

a)Brain-damaging mediators include proinflammatory cytokines, prostaglandins, reactive oxygen species, nitric oxide metabolites, excitatory amino acids, and rotavirus antigens such as nonstructural protein 4.
\end{abstract}

cell apoptosis in mice through Fas and Fas-L expression, ${ }^{92)}$ NSP4 may induce cell apoptosis via ROS.

\section{Possible routes of rotavirus invasion of the CNS}

To enter the CNS compartment from the primary site of infection, neurotrophic viruses are known to follow 3 routes: (1) crossing the vascular endothelium; (2) accessing peripheral nerves; and (3) "Trojan horse" entry. ${ }^{93)}$ Rotavirus is also presumed to exploit the first 2 routes to reach the CNS (Table 2).

\section{1) Hematogenous spread via blood-brain and blood-CSF} barriers and circumventricular organs

One of the most applauded mechanisms of viral invasion into the CNS is hematogenous spread across the vascular endothelium. Under normal conditions, the blood-brain and blood-CSF barriers are typically sufficient to protect the CNS from diverse insults including toxins, pathogens, and immune cells. Most blood vessels in the CNS are composed of nonfenestrated endothelial cells that have tight junctions that restrict the migration of cells and molecules through the interendothelial junction. ${ }^{94)}$ However, some neurotropic viruses use strategies that breach these barrier systems to enter the CNS. Several viruses, such as poliovirus, ${ }^{95)}$ Epstein-Barr virus, ${ }^{96}$ and West Nile virus, ${ }^{97)}$ directly infected human brain microvascular endothelial cell lines in vitro. Viral infection induces changes in endothelial cell properties, such as increased chemokine production, altered tight junction protein expression, and increased vascular cell adhesion molecule 1 expression. ${ }^{93)}$ These alterations potentially allow viruses to cross the vascular endothelium to reach the brain parenchyma. Under normal conditions, the choroid plexus epithelial cells act as a barrier between the systemic circulation and the CSF (blood-CSF barrier), with its predominantly tight junctions limiting paracellular diffusion, although the vascular endothelial cells at the choroid plexus are fenestrated and leaky. ${ }^{98-100)}$ Furthermore, hypoxia and inflammation disrupt barrier function. ${ }^{101)} \mathrm{A}$ recent study showed that the Zika virus enters the CNS through the blood-CSF barrier instead of the blood-brain barrier in a mouse model. ${ }^{102)}$ The other potential doorway for hematogenous viral spread is the circumventricular organs in the brain, including the area postrema, vascular organ of the lamina terminalis, subfornical organ, pineal gland, and median eminence of the hypothalamus, which contain highly permeable capillaries unlike the rest of the brain. ${ }^{103)}$
Rotavirus antigenemia is common in children with rotavirus infection. In one study, antigens were detected in 22 of 33 serum samples (66.7\%) from children with confirmed rotavirus infection versus none of the 35 samples from controls. ${ }^{104)}$ Surprisingly, another study showed that antigenemia was detected in $90 \%$ of children (51 of 57 cases) with rotavirus-positive stool and that infectious viruses were detected in 11 of 11 (100\%) serum samples (viremia) from serum antigen-positive children. ${ }^{105)}$ Detection rates of rotavirus RNA in the blood range from $0 \%$ to $64 \%$ in rotavirus-infected children and are not always concordant with the presence of antigenemia. ${ }^{105)}$

Meanwhile, one study showed that rotavirus-specific proteins were identified in macrophages and B cells in gut-associated lymphoid tissue (Peyer's patches and mesenteric lymph nodes) 2 days after the oral inoculation of murine rotavirus in mice. $\left.{ }^{106}\right)$ Furthermore, these antigen-containing immune cells were identified in extraintestinal (inguinal) lymph nodes 7 days after inoculation. These findings suggest that the lymphatic system may act as a way for rotavirus to exit the intestine. Since the lymphatic system ultimately merges into the subclavian veins, rotavirus or its antigens may spread throughout the body through the systemic circulation.

Considering the high incidence of antigenemia and viremia in children with rotavirus infection, in conjunction with the isolation of viral antigens and RNA from the CSF in patients with CNS complications due to rotavirus infection, hematogenous spread across the blood-brain barrier, blood-CSF barriers, and capillaries of the circumventricular organs is a potential route of viral invasion.

\section{2) Access via the peripheral nerves}

Peripheral nerves are another potential pathway for viral entry into the CNS. Herpes virus type 1 is a representative virus that uses the strategy of peripheral sensory neuronal cell infection for CNS entry. ${ }^{93)}$ Once viruses enter the peripheral neuronal cells, they are moved between the cell body and the synaptic junction using 2 axonal transport systems: (1) the "anterograde transport system" exploits kinesin for movement from the cell body (soma) to the synapse, while (2) the "retrograde system" uses dynein for migration from the synapse back to the cell body. ${ }^{107)}$ After arriving in the CNS, viral dissemination within the CNS can occur through release into synaptic clefts (e.g., herpes simplex virus and rabies virus) or via microfusion with neighboring 
neurons (e.g., measles virus). ${ }^{93)}$ Meanwhile, the gut has its own enteric nervous system that is uniquely organized with intrinsic microcircuits that facilitate the coordination of gastrointestinal function independent of the CNS. ${ }^{108}$ ) The vagal nerve is known to play a role in communication between the gut and the brain. The vagal afferents, accounting for $80 \%-90 \%$ of all fibers, send the "up" signals from the gut to the brain, and the vagal efferents, accounting for 10\%-20\%, send "down" signals from the brain to the gut. ${ }^{109)}$ Additionally, one study showed widespread distribution of endoplasmic reticulum-associated rotavirus proteins, outer capsid protein VP7 and nonstructural protein NSP4 in cell bodies and dendrites of the dorsal root ganglion and hippocampal neuronal cells of Sprague-Dawley rats infected by plaque purified rhesus rotavirus. ${ }^{85)}$ Although there are no reports on rotavirus infection in the vagus nerve, given that rotavirus and its proteins have been identified within cell bodies, dendrites, and axons of the neuronal cells in vitro, it can be presumed that rotavirus in the intestine might initially infect the vagus nerve and then reach the CNS. Further investigations are required to identify whether rotavirus can infect the vagus nerve in vitro and in vivo.

\section{CNS entry of circulating mediators produced by rotavirus infection}

In addition to direct viral invasion into the CNS, the entry of various circulating mediators produced during rotavirus infection into the CNS can be considered a possible mechanism of CNS complications. Circulating mediators include proinflam. matory cytokines, prostaglandins, ROS, nitric oxide metabolites, excitatory amino acids, and rotavirus antigens such as NSP4. ${ }^{103)}$ Systemic inflammation caused by various stimulants, such as viruses, polyinosinic:polycytidylic acid (poly I:C, a mimic of viral double-stranded RNA), cytokines such as IL-1 $\beta$, IL- 6 , and TNF- $\alpha$, and bacteria and lipopolysaccharide, can damage bloodbrain barrier integrity. ${ }^{10,111)}$ Thus, it is presumed that viremia or antigenemia, which often occurs in rotavirus infection as mentioned above, can cause systemic inflammation, thereby inducing a breach of the blood-brain barrier and blood-CSF barrier; eventually, the aforementioned deleterious mediators are able to enter the brain through the breach or the capillaries of the circumventricular organs.

Kawashima et al. ${ }^{112)}$ showed that NO2 and NO3 levels in the serum and CSF of rotavirus gastroenteritis patients with convulsions were significantly higher than those in the control group. This result suggests the possibility of circulating $\mathrm{NO}$ metabolites entering the CNS. Host immune responses to rotavirus infection may also cause brain injury. Clinical studies have shown that rotavirus gastroenteritis is associated with increased levels of proinflammatory cytokines, such as IL-1 $\beta$, IL6, IL-8, and interferon gamma (IFN- $\gamma){ }^{14,113)}$ Newborns with rotavirus-associated leukoencephalopathy have significantly higher IL-6, IFN- $\gamma$, and monocyte chemoattractant protein-1 levels in the CSF than the control group. ${ }^{114,115)}$ Furthermore, CSF IL-6 levels correlate positively with white matter lesion extent. A previous report showed elevated PGE2 and PGF2 levels in the plasma and stool of rotavirus-infected children. ${ }^{116)} \mathrm{A}$ clinical study showed that, in 19 children with CNS involvement associated with rotavirus infection, excitatory neurotransmitter levels (glutamate, glycine, and taurine) in the CSF were higher in patients with prolonged seizures accompanied by encephalopathy than in patients with a brief cluster of seizures without encephalopathy. ${ }^{117)}$

As mentioned earlier, viral encephalitis tends to demonstrate asymmetrical focal lesions on MRI as in herpes simplex virus encephalitis, while rotavirus-associated encephalopathy is generally characterized by bilateral symmetry, the predilection of cerebral white matter including the corpus callosum, and the lesions are well-demarcated, particularly on DWI. Considering these distinct features, it is likely that rotavirus-associated CNS complications may be attributed to the combined effects of CNS entry of various mediators and immune cells as well as virus and viral antigens across blood vessels in the brain rather than virusinduced cytopathic effects that developed after the direct viral infection of neurons and glial cells.

\section{CNS entry of activated circulating leukocytes}

Systemic inflammation caused by a viral infection can induce leukocytes in the blood vessels to transmigrate across the bloodbrain barrier, and leukocytes to reach the brain can injure neuronal cells. The presence of CSF pleocytosis in patients with acute rotavirus-associated encephalopathies/encephalitis and cerebellitis indicates the recruitment of leukocytes from circulation into the CNS. ${ }^{30,46)}$ The migration of leukocytes from the vascular lumen to the infected sites engages sequential adhesive molecular interactions between leukocytes and endothelial cells. ${ }^{118-121)}$ When viruses infect cells, various chemokines are produced and bind to their cognate chemokine receptors on circulating leukocytes, thereby activating leukocyte integrins, such as very late antigen 4 and lymphocyte function-associated antigen 1 , to cluster outside the cell membrane. ${ }^{118)}$ Besides, vascular endothelial cells enhance the expression of cell adhesion molecules such as vascular cell adhesion molecule 1 and intercellular adhesion molecule 1 , which are clustered in the luminal side of vessels after a viral infection. ${ }^{119)}$ Binding between integrins of circulating leukocytes and cell adhesion molecules on vascular endothelial cells leads to activation of the endothelial cell signaling pathway, which elicits opening of the tight and adherence junctions, and stress fiber formation (endothelial contraction) via actin remodeling. ${ }^{120,121)}$ These microstructural alterations facilitate passage of the leukocytes through the vascular endothelial cells (diapedesis) and eventual arrival at the inflamed site. Leukocytes that reach the brain can injure the neurons and glial cells.

\section{Considerations for future studies of the pathophysiology of rotavirus-associated CNS complications}

In future research on the pathophysiology of rotavirusassociated CNS complications, the following should be con- 
sidered. First, if rotavirus itself, its proteins and RNA, harmful mediators, and immune cells could induce brain lesions, what determines the specific lesion location? Second, what causes bilateral symmetry in brain lesions in almost all rotavirus infection-associated CNS complications? Third, why is cerebral white matter predominantly injured in most rotavirus infectionassociated CNS complications instead of cerebral gray matter, as seen in MERS, AESD, and neonatal rotavirus-associated leukoencephalopathy? Finally, what other possible mechanisms are at play in different types of rotavirus infection-associated CNS complications?

\section{Conclusion}

Although rotavirus is a well-known most common cause of pediatric gastroenteritis worldwide, rotavirus infection-associated CNS complications have been relatively overlooked. However, rotavirus infection-associated CNS complications are fairly common in children and their clinicoradiological features are diverse. These have been classified mainly on the basis of the clinical features and characteristics of brain MRI, particularly lesion location on DWI. Common clinicoradiological features of rotavirus infection-associated CNS complications include benign convulsions with mild gastroenteritis and acute encephalopathies/encephalitis such as MERS, AESD, ANE, acute cerebellitis, and neonatal rotavirus-associated leukoencephalopathy. Despite a variety of clinical and laboratory studies, the precise mechanisms underlying these complications remain unknown. The direct viral invasion into the brain via several potential pathways, such as the blood-brain and blood-CSF barriers and vagus nerve, and the entry of activated immune cells and various brain-damaging mediators into the brain through the breach of blood vessels in the brain, are potential mechanisms for rotavirus infection-associated CNS complications. Further investigations are needed to elucidate the pathophysiology of each type of rotavirus infection-associated CNS complications. Moreover, proper treatment strategies should be identified according to the pathophysiology.

See the commentary on "Increasing our understanding of rotavirus-induced central nervous system manifestations" via https://doi.org/10.3345/cep.2022.00395.

\section{Footnotes}

Conflicts of interest: No potential conflict of interest relevant to this article was reported.

Funding: This study received no specific grant from any funding agency in the public, commercial, or not-for-profit sectors.
ORCID:

Kyung Yeon Lee @ https://orcid.org/0000-0001-6821-1056

\section{References}

1. Crawford SE, Ramani S, Tate JE, Parashar UD, Svensson L, Hagbom M, et al. Rotavirus infection. Nat Rev Dis Primers 2017;3:17083.

2. Tate JE, Burton AH, Boschi-Pinto C, Steele AD, Duque J, Parashar UD, et al. 2008 estimate of worldwide rotavirus-associated mortality in children younger than 5 years before the introduction of universal rotavirus vaccination programmes: a systematic review and meta-analysis. Lancet Infect Dis 2012;12:136-41.

3. Burnett E, Parashar UD, Tate JE. Real-world effectiveness of rotavirus vaccines, 2006-19: a literature review and meta-analysis. Lancet Glob Health 2020;8:e1195-202.

4. Parashar UD, Hummelman EG, Bresee JS, Miller MA, Glass RI. Global illness and deaths caused by rotavirus disease in children. Emerg Infect Dis 2003;9:565-72.

5. Burnett E, Jonesteller CL, Tate JE, Yen C, Parashar UD. Global impact of rotavirus vaccination on childhood hospitalizations and mortality from diarrhea. J Infect Dis 2017;215:1666-72.

6. Kawase M, Hoshina T, Yoneda T, Kojiro M, Takahashi Y, Kusuhara K. The changes of the epidemiology and clinical characteristics of rotavirus gastroenteritis-associated convulsion after the introduction of rotavirus vaccine. J Infect Chemother 2020;26:206-10.

7. Hungerford DJ, French N, Iturriza-Gómara M, Read JM, Cunliffe NA, Vivancos R. Reduction in hospitalisations for acute gastroenteritisassociated childhood seizures since introduction of rotavirus vaccination: a time-series and change-point analysis of hospital admissions in England. JEpidemiol Community Health 2019;73:1020-5.

8. Salas A, Pardo-Seco J, Cebey-López M, Martinón-Martínez JM, Gómez-Rial J, Currás-Tuala MJ, et al. Impact of rotavirus vaccination on childhood hospitalizations for seizures: Heterologous or unforeseen direct vaccine effects? Vaccine 2019;37:3362-8.

9. Pringle KD, Burke RM, Steiner CA, Parashar UD, Tate JE. Trends in rate of seizure-associated hospitalizations among children $<5$ years old before and after rotavirus vaccine introduction in the United Sates, 2000-2013. J Infect Dis 2018;217:581-8.

10. Park SH, Kim YO, Kim HK, Kim HS, Kim BY, Cheon KR, et al. Incidence of benign convulsions with mild gastroenteritis after introduction of rotavirus vaccine. Brain Dev 2015;37:625-30.

11. Payne DC, Baggs J, Zerr DM, Klein NP, Yih K, Glanz J, et al. Protective association between rotavirus vaccination and childhood seizures in the year following vaccination in US children. Clin Infect Dis 2014;58:173-7.

12. Tate JE, Burton AH, Boschi-Pinto C, Parashar UD; World Health Organization-Coordinated Global Rotavirus Surveillance Network. Global, regional, and national estimates of rotavirus mortality in children $<5$ years of age, 2000-2013. Clin Infect Dis 2016;62 Suppl 2:S96-105.

13. Bishop RF, Davidson GP, Holmes IH, Ruck BJ. Virus particles in epithelial cells of duodenal mucosa from children with acute non-bacterial gastroenteritis. Lancet 1973;2:1281-3.

14. Dian Z, Sun Y, Zhang G, Xu Y, Fan X, Yang X, et al. Rotavirus-related systemic diseases: clinical manifestation, evidence and pathogenesis. Crit Rev Microbiol 2021;47:580-95.

15. Gómez-Rial J, Sánchez-Batán S, Rivero-Calle I, Pardo-Seco J, MartinónMartínez JM, Salas A, et al. Rotavirus infection beyond the gut. Infect Drug Resist 2018;12:55-64.

16. Mizuguchi M, Ichiyama T, Imataka G, Okumura A, Goto T, Sakuma H, et al. Guidelines for the diagnosis and treatment of acute encephalopathy in childhood. Brain Dev 2021;43:2-31.

17. Hoshino A, Saitoh M, Oka A, Okumura A, Kubota M, Saito Y, et al. Epidemiology of acute encephalopathy in Japan, with emphasis on the association of viruses and syndromes. Brain Dev 2012;34:337-43.

18. Kasai M, Shibata A, Hoshino A, Maegaki Y, Yamanouchi H, Takanashi JI, 
et al. Epidemiological changes of acute encephalopathy in Japan based on national surveillance for 2014-2017. Brain Dev 2020;42:508-14.

19. Fowler Å, Ygberg S, Svensson E, Bergman K, Cooray G, Wickström R. Prospective evaluation of childhood encephalitis: predisposing factors, prevention and outcome. Pediatr Infect Dis J 2020;39:e417-22.

20. Salmi TT, Arstila P, Koivikko A. Central nervous system involvement in patients with rotavirus gastroenteritis. Scand J Infect Dis 1978;10:29-31.

21. Abe T, Kobayashi M, Araki K, Kodama H, Fujita Y, Shinozaki T, et al. Infantile convulsions with mild gastroenteritis. Brain Dev 2000;22:301-6.

22. Dura-Trave T, Yoldi-Petri ME, Gallinas-Victoriano F, Molins-Castiella T. Infantile convulsions with mild gastroenteritis: a retrospective study of 25 patients. Eur J Neurol 2011;18:273-8.

23. DiFazio MP, Braun L, Freedman S, Hickey P. Rotavirus-induced seizures in childhood. J Child Neurol 2007;22:1367-70.

24. Wong CJ, Price Z, Bruckner DA. Aseptic meningitis in an infant with rotavirus gastroenteritis. Pediatr Infect Dis 1984;3:244-6.

25. Fuchigami T, Goto K, Hasegawa M, Saito K, Kida T, Hashimoto K, et al. A 4-year-old girl with clinically mild encephalopathy with a reversible splenial lesion associated with rotavirus infection. J Infect Chemother 2013;19:149-53.

26. Fukuda S, Kishi K, Yasuda K, Sejima H, Yamaguchi S. Rotavirus-associated encephalopathy with a reversible splenial lesion. Pediatr Neurol 2009; 40:131-3.

27. Arakawa C, Fujita Y, Imai Y, Ishii W, Kohira R, Fuchigami T, et al. Detection of group a rotavirus RNA and antigens in serum and cerebrospinal fluid from two children with clinically mild encephalopathy with a reversible splenial lesion. Jpn J Infect Dis 2011;64:204-7.

28. Dickey M, Jamison L, Michaud L, Care M, Bernstein DI, Staat MA. Rotavirus meningoencephalitis in a previously healthy child and a review of the literature. Pediatr Infect Dis J 2009;28:318-21.

29. Shiihara T, Watanabe M, Honma A, Kato M, Morita Y, Ichiyama T, et al. Rotavirus associated acute encephalitis/encephalopathy and concurrent cerebellitis: report of two cases. Brain Dev 2007;29:670-3.

30. Takanashi J, Miyamoto T, Ando N, Kubota T, Oka M, Kato Z, et al. Clinical and radiological features of rotavirus cerebellitis. AJNR Am J Neuroradiol 2010;31:1591-5.

31. Lloyd MB, Lloyd JC, Gesteland PH, Bale JF. Rotavirus gastroenteritis and seizures in young children. Pediatr Neurol 2010;42:404-8.

32. Pardo-Seco J, Cebey-López M, Martinón-Torres N, Salas A, GómezRial J, Rodriguez-Tenreiro C, et al. Impact of rotavirus vaccination on childhood hospitalization for seizures. Pediatr Infect Dis J 2015;34:76973.

33. Lynch M, Lee B, Azimi P, Gentsch J, Glaser C, Gilliam S, et al. Rotavirus and central nervous system symptoms: cause or contaminant? Case reports and review. Clin Infect Dis 2001;33:932-8.

34. Castellazzi L, Principi N, Agostoni C, Esposito S. Benign convulsions in children with mild gastroenteritis. Eur J Paediatr Neurol 2016;20:690-5.

35. Kang B, Kim DH, Hong YJ, Son BK, Kim DW, Kwon YS. Comparison between febrile and afebrile seizures associated with mild rotavirus gastroenteritis. Seizure 2013;22:560-4.

36. Hung JJ, Wen HY, Yen MH, Chen HW, Yan DC, Lin KL, et al. Rotavirus gastroenteritis associated with afebrile convulsion in children: clinical analysis of 40 cases. Chang Gung Med J 2003;26:654-9.

37. MaX, Luan S, Zhao Y, Lv X, Zhang R. Clinical characteristics and followup of benign convulsions with mild gastroenteritis among children. Medicine (Baltimore) 2019;98:e14082.

38. Cusmai R, Jocic-Jakubi B, Cantonetti L, Japaridze N, Vigevano F. Convulsions associated with gastroenteritis in the spectrum of benign focal epilepsies in infancy: 30 cases including four cases with ictal EEG recording. Epileptic Disord 2010;12:255-61.

39. Ogawa C, Kidokoro H, Ishihara N, Tsuji T, Kurahashi H, Hattori A, et al. Splenial lesions in benign convulsions with gastroenteritis associated with rotavirus infection. Pediatr Neurol 2020;109:79-84.

40. Nishimura S, Ushijima H, Nishimura S, Shiraishi H, Kanazawa C, Abe T, et al. Detection of rotavirus in cerebrospinal fluid and blood of patients with convulsions and gastroenteritis by means of the reverse transcription polymerase chain reaction. Brain Dev 1993;15:457-9.
41. Yoshida A, Kawamitu T, Tanaka R, Okumura M, Yamakura S, Takasaki Y, et al. Rotavirus encephalitis: detection of the virus genomic RNA in the cerebrospinal fluid of a child. Pediatr Infect Dis J 1995;14:914-6.

42. Payne DC, Vinje J, Szilagyi PG, Edwards KM, Staat MA, Weinberg GA, et al. Norovirus and medically attended gastroenteritis in U.S. children. N Engl J Med 2013;368:1121-30.

43. Mizuguchi M, Yamanouchi $\mathrm{H}$, Ichiyama T, Shiomi M. Acute encephalopathy associated with influenza and other viral infections. Acta Neurol Scand 2007;115:45-56.

44. Ellul M, Solomon T. Acute encephalitis - diagnosis and management. Clin Med (Lond) 2018;18:155-9.

45. Tyler KL. Acute viral encephalitis. NEngl J Med 2018;379:557-66.

46. Kawamura Y, Ohashi M, Ihira M, Hashimoto S, Taniguchi K, Yoshikawa T. Nationwide survey of rotavirus-associated encephalopathy and sudden unexpected death in Japan. Brain Dev 2014;36:601-7.

47. Tada H, Takanashi J, Barkovich AJ, Oba H, Maeda M, Tsukahara H, et al. Clinically mild encephalitis/encephalopathy with a reversible splenial lesion. Neurology 2004;63:1854-8.

48. Takanashi J. Two newly proposed infectious encephalitis/encephalopathy syndromes. Brain Dev 2009;31:521-8.

49. Matsuoka T, Yodoshi T, Sugai M, Hiyane M, Matsuoka T, Akeda H, et al. A case of mild encephalopathy with a reversible splenial lesion associated with G5P[6] rotavirus infection. Case Rep Pediatr 2013;2013:197163.

50. Takanashi J, Oba H, Barkovich AJ, Tada H, Tanabe Y, Yamanouchi H, et al. Diffusion MRI abnormalities after prolonged febrile seizures with encephalopathy. Neurology 2006;66:1304-9.

51. Takanashi J, Tada H, Terada H, Barkovich AJ. Excitotoxicity in acute encephalopathy with biphasic seizures and late reduced diffusion. Report of 3 cases. Am J Neuroradiol 2009;30:132-5.

52. Yamaguchi $\mathrm{H}$, Nishiyama M, Tokumoto S, Ishida Y, Tomioka K, Aoki K, et al. Detailed characteristics of acute encephalopathy with biphasic seizures and late reduced diffusion: 18-year data of a single-center consecutive cohort. J Neurol Sci 2020;411:116684.

53. Mizuguchi M. Acute necrotizing encephalopathy of childhood: a novel form of acute encephalopathy prevalent in Japan and Taiwan. Brain Dev 1997;19:81-92.

54. Kim JH, Kim IO, Lim MK, Park MS, Choi CG, Kim HW, et al. Acute necrotizing encephalopathy in Korean infants and children: imaging findings and diverse clinical outcome. Korean J Radiol 2004;5:171-7.

55. Low YY, Lin HC, Wu FT, Chou IC, Hwang KP. Detection of rotavirus antigen in a child with acute necrotizing encephalopathy. J Formos Med Assoc 2021;120:1029-31.

56. Lee CG, Kim JH, Lee M, Lee J. Clinical outcome of acute necrotizing encephalopathy in related to involving the brain stem of single institution in Korea. Korean J Pediatr 2014;57:264-70.

57. Okumura A, Mizuguchi M, Kidokoro H, Tanaka M, Abe S, Hosoya M, et al. Outcome of acute necrotizing encephalopathy in relation to treatment with corticosteroids and gammaglobulin. Brain Dev 2009;31:211-7.

58. Wong AM, Simon EM, Zimmerman RA, Wang HS, Toh CH, Ng SH. Acute necrotizing encephalopathy of childhood: correlation of MR findings and clinical outcome. AJNR Am J Neuroradiol 2006;27:191923.

59. Mizuguchi M. Acute necrotizing encephalopathy. Nihon Rinsho 2011; 69:465-70.

60. Davies NW, Sharief MK, Howard RS. Infection-associated encephalopathies: their investigation, diagnosis, and treatment. J Neurol 2006; 253:833-45.

61. Weitkamp JH, Spring MD, Brogan T, Moses H, Bloch KC, Wright PF. Influenza A virus-associated acute necrotizing encephalopathy in the United States. Pediatr Infect Dis J 2004;23:259-63.

62. Kubota T, Suzuki T, Kitase Y, Kidokoro H, Miyajima Y, Ogawa A, et al. Chronological diffusion-weighted imaging changes and mutism in the course of rotavirus-associated acute cerebellitis/cerebellopathy concurrent with encephalitis/encephalopathy. Brain Dev 2011;33:21-7.

63. Mori T, Morii M, Kuroiwa Y, Hotsubo T, Fuse S, Tsustumi H. Rotavirus encephalitis and cerebellitis with reversible magnetic resonance signal changes. Pediatr Int 2011;53:252-5. 
64. Lee KY, Oh KW, Weon YC, Choi SH. Neonatal seizures accompanied by diffuse cerebral white matter lesions on diffusion-weighted imaging are associated with rotavirus infection. Eur J Paediatr Neurol 2014;18:62431.

65. Oh KW, Lim G, Lee KY. Neonatal rotavirus-associated leukoencephalopathy is one of the main causes of fifth-day fits. J Child Neurol 2021;36: 378-84.

66. Oh KW, Moon $\mathrm{CH}$, Lee KY. Association of rotavirus with seizures accompanied by cerebral white matter injury in neonates. J Child Neurol 2015;30:1433-9.

67. Ku JK, Heo YJ, Lee KS, Lee BL. Clinical findings and neurologic outcome in neonatal encephalopathy with white matter injury accompanied by rotavirus. J Child Neurol 2018;33:297-305.

68. Yeom JS, Kim YS, Seo JH, Park JS, Park ES, Lim JY, et al. Distinctive pattern of white matter injury in neonates with rotavirus infection. Neurology 2015;84:21-7.

69. Lee KY, Weon YC, Choi SH, Oh KW, Park H. Neurodevelopmental outcomes in newborns with neonatal seizures caused by rotavirusassociated leukoencephalopathy. Seizure 2018;56:14-9.

70. Lee DJ, Kim JS. Rotavirus infection-associated posterior reversible encephalopathy syndrome. Ann Child Neurol 2019;27:60-2.

71. Ki Pang K, Lynch BJ, Osborne JP, Pike MG. Dancing eye syndrome associated with spontaneous recovery and normal neurodevelopment. Eur J Paediatr Neurol 2010;14:178-81.

72. Shimakawa S, Nomura S, Ogino M, Fukui M, Kashiwagi M, Tanabe T, et al. ACTH therapy on intractable epilepsy in hemiconvulsion-hemiplegiaepilepsy syndrome. Brain Dev 2015;37:733-7.

73. Iturriza-Gómara M, Auchterlonie IA, Zaw W, Molyneaux P, Desselberger $\mathrm{U}$, Gray J. Rotavirus gastroenteritis and central nervous system (CNS) infection: characterization of the VP7 and VP4 genes of rotavirus strains isolated from paired fecal and cerebrospinal fluid samples from a child with CNS disease. J Clin Microbiol 2002;40:4797-9.

74. Liu B, Fujita Y, Arakawa C, Kohira R, Fuchigami T, Mugishima H, et al. Detection of rotavirus RNA and antigens in serum and cerebrospinal fluid samples from diarrheic children with seizures. Jpn J Infect Dis 2009;62:279-83.

75. Medici MC, Abelli LA, Guerra P, Dodi I, Dettori G, Chezzi C. Case report: detection of rotavirus RNA in the cerebrospinal fluid of a child with rotavirus gastroenteritis and meningism. J Med Virol 2011;83:163740.

76. Sadiq A, Bostan N, Yinda KC, Naseem S, Sattar S. Rotavirus: genetics, pathogenesis and vaccine advances. Rev Med Virol 2018;28:e2003.

77. Trask SD, McDonald SM, Patton JT. Structural insights into the coupling of virion assembly and rotavirus replication. Nat Rev Microbiol 2012;10:165-77.

78. Infantile enteritis viruses: morphogenesis and morphology. J Virol 1975;16:937-43.

79. Davidson GP, Barnes GL. Structural and functional abnormalities of the small intestine in infants and young children with rotavirus enteritis. Acta Paediatr Sand 1979;68:181-6.

80. Boshuizen JA, Reimerink JH, Korteland-van Male AM, van Ham VJ, Koopmans MP, Büller HA, et al. Changes in small intestinal homeostasis, morphology, and gene expression during rotavirus infection of infant mice. J Virol 2003;77:13005-16.

81. Tafazoli F, Zeng CQ, Estes MK, Magnusson KE, Svensson L. NSP4 enterotoxin of rotavirus induces paracellular leakage in polarized epithelial cells. J Virol 2001;75:1540-6.

82. Boshuizen JA, Rossen JW, Sitaram CK, Kimenai FF, Simons-Oosterhuis Y, Laffeber C, et al. Rotavirus enterotoxin NSP4 binds to the extracellular matrix proteins laminin-beta3 and fibronectin. J Virol 2004;78:1004553.

83. Hyser JM, Collinson-Pautz MR, Utama B, Estes MK. Rotavirus disrupts calcium homeostasis by NSP4 viroporin activity. mBio 2010;1:e026510.

84. Weclewicz K, Kristensson K, Greenberg HB, Svensson L. The endoplasmic reticulum-associated VP7 of rotavirus is targeted to axons and dendrites in polarized neurons. J Neurocytol 1993;22:616-26.
85. Weclewicz K, Svensson L, Kristensson K. Targeting of endoplasmic reticulum-associated proteins to axons and dendrites in rotavirus-infected neurons. Brain Res Bull 1998;46:353-60.

86. Pham T, Perry JL, Dosey TL, Delcour AH, Hyser JM. The Rotavirus NSP4 viroporin domain is a calcium-conducting ion channel. Sci Rep 2017;7:43487.

87. Rodríguez-Díaz J, Banasaz M, Istrate C, Buesa J, Lundgren O, Espinoza F, et al. Role of nitric oxide during rotavirus infection. J Med Virol 2006;78:979-85.

88. Valko M, Leibfritz D, Moncol J, Cronin MT, Mazur M, Telser J. Free radicals and antioxidants in normal physiological functions and human disease. Int J Biochem Cell Biol 2007;39:44-84.

89. Borghan MA, Mori Y, El-Mahmoudy AB, Ito N, Sugiyama M, Takewaki $\mathrm{T}$, et al. Induction of nitric oxide synthase by rotavirus enterotoxin NSP4: implication for rotavirus pathogenicity. J Gen Virol 2007;88:2064-72.

90. Ge Y, Mansell A, Ussher JE, Brooks AE, Manning K, Wang CJ, et al. Rotavirus NSP4 triggers secretion of proinflammatory cytokines from macrophages via Toll-like receptor 2. J Virol 2013;87:11160-7.

91. Buccigrossi V, Laudiero G, Russo C, Miele E, Sofia M, Monini M, et al. Chloride secretion induced by rotavirus is oxidative stress-dependent and inhibited by Saccharomyces boulardii in human enterocytes. PLoS One 2014;9:e99830.

92. Denning TL, Takaishi H, Crowe SE, Boldogh I, Jevnikar A, Ernst PB. Oxidative stress induces the expression of Fas and Fas ligand and apoptosis in murine intestinal epithelial cells. Free Radic Biol Med 2002;33:164150.

93. McGavern DB, Kang SS. Illuminating viral infections in the nervous system. Nat Rev Immunol 2011;11:318-29.

94. Bechmann I, Galea I, Perry VH. What is the blood-brain barrier (not)? Trends Immunol 2007;28:5-11.

95. Coyne CB, Kim KS, Bergelson JM. Poliovirus entry into human brain microvascular cells requires receptor-induced activation of SHP-2. EMBO J 2007;26:4016-28.

96. Casiraghi C, Dorovini-Zis K, Horwitz MS. Epstein-Barr virus infection of human brain microvessel endothelial cells: a novel role in multiple sclerosis. J Neuroimmunol 2011;230:173-7.

97. Verma S, Kumar M, Gurjav U, Lum S, Nerurkar VR. Reversal of West Nile virus-induced blood-brain barrier disruption and tight junction proteins degradation by matrix metalloproteinases inhibitor. Virology 2010;397:130-8.

98. Dunn JF, Isaacs AM. The impact of hypoxia on blood-brain, blood-CSF, and CSF-brain barriers. J Appl Physiol 2021;131:977-85.

99. Redzic Z. Molecular biology of the blood-brain and the blood-cerebrospinal fluid barriers: similarities and differences. Fluids Barriers CNS 2011;8:3.

100. Engelhardt B, Sorokin L. The blood-brain and the blood-cerebrospinal fluid barriers: function and dysfunction. Semin Immunopathol 2009;31: 497-511.

101. Nathoo N, Jalal H, Natah SS, Zhang Q, Wu Y, Dunn JF. Hypoxia and inflammation-induced disruptions of the blood-brain and bloodcerebrospinal fluid barriers assessed using a novel T1-based MRI method. Acta Neurochir 2016;Suppl 121:23-8.

102. Kim J, Alejandro B, Hetman M, Hattab EM, Joiner J, Schroten H, et al. Zika virus infects pericytes in the choroid plexus and enters the central nervous system through the blood-cerebrospinal fluid barrier. PLoS Pathog 2020;16:e1008204.

103. Hellysaz A, Hagbom M. Understanding the central nervous system symptoms of rotavirus: a qualitative review. Viruses 2021;13:658.

104. Blutt SE, Kirkwood CD, Parreño V, Warfield KL, Ciarlet M, Estes MK, et al. Rotavirus antigenaemia and viraemia: a common event? Lancet 2003;362:1445-9.

105. Blutt SE, Matson DO, Crawford SE, Staat MA, Azimi P, Bennett BL, et al. Rotavirus antigenemia in children is associated with viremia. PLoS Med 2007;4:e121.

106. Brown KA, Offit PA. Rotavirus-specific proteins are detected in murine macrophages in both intestinal and extraintestinal lymphoid tissues. Microb Pathog 1998;24:327-31. 
107. Hsieh MJ, White PJ, Pouton CW. Interaction of viruses with host cell molecular motors. Curr Opin Biotechnol 2010;21:633-9.

108. Rao M, Gershon MD. The bowel and beyond: the enteric nervous system in neurological disorders. Nat Rev Gastroenterol Hepatol 2016;13:517-28.

109. Breit S, Kupferberg A, Rogler G, Hasler G. Vagus nerve as modulator of the brain-gut axis in psychiatric and inflammatory disorders. Front Psychiatry 2018;9:44.

110. Elwood E, Lim Z, Naveed H, Galea I. The effect of systemic inflammation on human brain barrier function. Brain Behav Immun 2017;62: $35-40$.

111. Varatharaj A, Galea I. The blood-brain barrier in systemic inflammation. Brain Behav Immun 2017;60:1-12.

112. Kawashima H, Inage Y, Ogihara M, Kashiwagi Y, Takekuma K, Hoshika A, et al. Serum and cerebrospinal fluid nitrite/nitrate levels in patients with rotavirus gastroenteritis induced convulsion. Life Sci 2004;74:1397-405.

113. Mormile R. Severe gastroenteritis and acute pancreatitis following rotavirus infection in children: the age-related failure of IFN- $\gamma$ ? Immunol Lett 2016;175:58-9.

114. Lee KY, Moon CH, Choi SH. Type I interferon and proinflammatory cytokine levels in cerebrospinal fluid of newborns with rotavirusassociated leukoencephalopathy. Brain Dev 2018;40:211-7.

115. Yeom JS, Jo JY, Park JS, Kim YS, Chung JY, Han TH, et al. Monocyte chemoattractant protein (MCP)-1 in rotavirus-associated white matter injury in newborns. Neuropediatrics 2019;50:228-34.

116. Yamashiro Y, Shimizu T, Oguchi S, Sato M. Prostaglandins in the plasma and stool of children with rotavirus gastroenteritis. J Pediatr Gastroenterol Nutr 1989;9:322-7.

117. Kashiwagi Y, Kawashima H, Suzuki S, Nishimata S, Takekuma K, Hoshika A. Marked elevation of excitatory amino acids in cerebrospinal fluid obtained from patients with rotavirus-associated encephalopathy. J Clin Lab Anal 2015;29:328-33.

118. Imhof BA, Aurrand-Lions M. Adhesion mechanisms regulating the migration of monocytes. Nat Rev Immunol 2004;4:432-44.

119. Schnoor M. Endothelial actin-binding proteins and actin dynamics in leukocyte transendothelial migration. J Immunol 2015;194:3535-41.

120. Vestweber D. How leukocytes cross the vascular endothelium. Nat Rev Immunol 2015;15:692-704.

121. Nourshargh S, Hordijk PL, Sixt M. Breaching multiple barriers: leukocyte motility through venular walls and the interstitium. Nat Rev Mol Cell Biol 2010;11:366-78.

How to cite this article: Lee KY. Rotavirus infectionassociated central nervous system complications: clinicoradiological features and potential mechanisms. Clin Exp Pediatr 2022; 65:783-93. https://doi.org/10.3345/cep. 2021.01333 